\title{
Feeding Selectivity of Montane and LONG-TAILED VoleS
}

\author{
FREDERICK J. JANNETT, JR. \\ Department of Biology $\downarrow$ The Science Museum of Minnesota \\ St. Paul
}

\section{$\downarrow$ OBJeCtives}

Microtus longicaudus exhibits relatively stable numbers while $M$. montanus has dramatic fluctuations in some habitats. The study sites for $M$. montanus have been chosen to include primary and secondary habitat, and proximate and isolated habitat patches. Vegetation has heretofore not been quantitatively analyzed. The purpose of the research begun in 1989 is to ascertain how selectively these species feed, and to assess vegetation as a factor in demographic processes in the two species.

\section{$\downarrow$ MethodS}

Virtually all previous work on these species by the author (1971-1977, 1982-1988) involved live trapping. The present work requires specimens obtained in Museum Special traps for stomach content analysis. The trapping begun in 1989 is a preliminary effort, the purpose of which was to assess the efficacy of Museum Special traps. The number of sites where $M$. longicaudus were trapped was increased across a spectrum of vegetation types. Only three populations of this species were monitored from 1982-1988. Also, at three sites with populations of $M$. montanus, live traps are still being deployed to secure voles. It is hoped that, by replicating previous efforts at these three sites, work on food habits can be related to changes in vole numbers. For this end, the three sites chosen for continued monitoring with live traps were one field having definite population fluctuations, one site peripheral to primary habitat, and one site of secondary habitat.

Most trapping periods were limited to two days so that impact on populations would be minimized. From fresh specimens, eyes were removed for age determination upon lens weight (Gourley and Jannett, 1975). For another researcher's DNA-DNA recombination research, an effort was made to secure specimens of heather voles (Phenacomys intermedius). Lastly, for another geneticist, material for $M$. pennsylvanicus karyotype preparations was secured elsewhere in Jackson Hole outside Grand Teton National Park.

\section{$\downarrow \quad$ ResUlts}

At two sites the populations of $M$. montanus increased from October, 1989 to October, 1990 by factors of 4.6 and 14 , respectively. But in secondary habitat, the number of voles merely increased from 0 to 2 .

In one of the two larger samples there was no first pregnancy female or reproductively active parous female (out of eight parous females); one lactating and one pregnant female were among five parous females in the other sample. 
Time and weather permitted the author to find two additional $M$. longicaudus sites. Tissues were secured from a small series of $M$. pennsylvanicus and three $P$. intermedius.

\section{$\downarrow \quad$ Discussion}

Eighteen populations of $M$. montanus were previously identified 1982-1988, but only six of $M$. longicaudus have been located to date. Considerable effort is planned for 1991 to find more, preliminary to vegetation and gut analyses.

Continued monitoring of three $M$. montanus sites is showing disparity in population size trends within one year. Whether there is concomitant disparity in morphological patters among specimens is uncertain.

\section{$\downarrow$ ACKNOWLEDGEMENTS}

I thank the National Park Service for permission to work in Grand Teton National Park, and the University of Wyoming-National Park Service Research Center for facilities. This work was supported by the Science Museum of Minnesota.

\section{$\downarrow \quad$ Literature Cited}

Gourley, R. S. and F. J. Jannett, Jr. 1975. Pine and montane vole age estimates from eye lens weights. J. Wildl. Manage. 39:550-556. 